\title{
A METHOD FOR PLACE NAME DISPLAY CONSIDERING USER LOCATING HABITS IN MAP SITES
}

\author{
Liu Xiaochun ${ }^{\text {a }}$, LiXiang a ${ }^{\text {, WangLina a }}{ }^{\text {, WangPei }}{ }^{\text {a }}$ \\ a Information Engineering University, Zhengzhou 450052, China-253807321@qq.com
}

\section{Commission}

KEY WORDS: user, web based, experiment, cartography, test

\begin{abstract}
:
The traditional researches for cartographic lettering and display focus on conflict among labels and overlap between labels and features. But these two issues are not significant in web maps. It is worthwhile to concern about how to improve labels' readability considering user locating habits for enhancing user experience. This paper has established a new method for place name display called "the gravitational field". This method is appropriate for the display of dotted place names from the national level (approximately 1:20 million) to city level (approximately 1:250 thousand) in web maps. We have conducted a usability test which used all nationwide provincial capitals, autonomous regions, municipalities, prefecture-level cities, municipal districts, countries and part of the townships dotted names. The results show that this rule improves web map's legibility, and can significantly enhance the user experience.
\end{abstract}

\section{INTRODUCTION}

According to incomplete statistics, First impression of a small scale map is its cartographic lettering [1], and the Place Name label is the main content of cartographic lettering, especially on the web map. In this way, research on display method for place label is an effective way to improve the network map legibility.

Mainly from three aspects domestic and foreign scholars research how to improve the visual effect of cartographic lettering. One method is based on long-term drawing experience; summarize some rules of label design ${ }^{[2-6]}$. The second method is based on the psychology experiment, study the effects of font, color and position on map legibility $[1,7,8]$. The third will transform graphics expert's label design experience into knowledge, and then through the computer to configure the label automatically, in other words, research on algorithm of automatic configuration of cartographic lettering ${ }^{[9]}$.These researches solved the problem of cartographic lettering on the map, especially the conflicts and overlaps on paper maps, but is not fully applicable to the web map. Specifically for, it includes the following two aspects:

(1) In the past, optimizing the place label including three targets: the fewest conflicts, the best position of place label and the minimum overlap on other geographical factors. The optimal location of place label is merely considered to be an aesthetic requirement; therefore its priority is the lowest. Web map is organized on different map scale; place label does not need to be placed in a single level, so the problem of conflict and overlap is not significant. Take Baidu map as an example, table 1 is a different level of place label the Baidu map display in some scales. At the end of 2005, the number of all the provinces, autonomous regions, special administrative region, provincial capital, prefecture level city, county, township, can be roughly estimated the maximum density of place label on the Baidu Map is $2.59 \mathrm{~mm} 2 / \mathrm{cm} 2$ (between the $3 \sim 9$ class), this value is far lower than the measured settlements of maximum load on the normal $\operatorname{map}(15 \mathrm{~mm} 2 / \mathrm{cm} 2)$, is also lower than the load of the most appropriate $(12 \mathrm{~mm} 2 / \mathrm{cm} 2)$. So the research on display rules of place label on the web map, can be assumed that conflict and overlap problems have been solved effectively or in the absence 
The International Archives of the Photogrammetry, Remote Sensing and Spatial Information Sciences, Volume XL-4/W3, 2013 ISPRS/IGU/ICA Joint Workshop on Borderlands Modelling and Understanding for Global Sustainability 2013,

\section{5 - 6 December 2013, Beijing, China}

of these problem, focuses on how to effectively improve the map legibility through optimal position of place label.

(2) Web map pays more attention to the user experience than any previous map products. So the web map should not only take the clarity, beauty and unambiguity of label into account, more attention should be paid to the user's habit when they are searching and locating the place names. Users often use high-level names as reference to find the location. Map website highlight the high-level place label by significantly increase font size, word color or desalinize low grade place label. The disadvantage of this approach is that the high-level place label is too eye-catching, easy to distract the user's attention. As Robinson said, "the best label design is that when they do not need to be read, they are not distracting" ${ }^{[1]}$.In addition, the user will zoom in and out on the map frequently in searching and locating names. In this operation, the user can easily lose the place label. How visual design makes the focus of place label not easy to loss is one of the effective ways to improve the user experience.

This paper establishes and implements a web map display rule of place label of similar "gravity". This rule applies to the change and display of point from the national level (about 1:2000 million) to the city level (about 1:25 million), considered of the user habit in searching the place names, can effectively enhance the user experience.

Tab 1 Place names display for various map scales(Baidu Map)

\begin{tabular}{|c|c|c|c|c|c|c|c|}
\hline & $\begin{array}{c}\text { Special } \\
\text { Administrative } \\
\text { Region / } \\
\text { municipality }\end{array}$ & $\begin{array}{c}\text { provincial } \\
\text { capital }\end{array}$ & $\begin{array}{c}\text { Prefecture level } \\
\text { city/ Autonomous } \\
\text { Prefecture/ } \\
\text { League/ area }\end{array}$ & $\begin{array}{l}\text { municipal } \\
\text { district }\end{array}$ & $\begin{array}{c}\text { County/ county- } \\
\text { level cities / } \\
\text { other }\end{array}$ & $\begin{array}{l}\text { Xiang/ } \\
\text { town/ } \\
\text { other }\end{array}$ & $\begin{array}{l}\text { Map lable load } \\
\mathrm{mm} 2 / \mathrm{cm} 2)\end{array}$ \\
\hline 3 level(1:19000000) & $\sqrt{ }$ & $\sqrt{ }$ & & & & & 2.59 \\
\hline 4 level(1:95000000) & $\sqrt{ }$ & $\sqrt{ }$ & & & & & 0.65 \\
\hline 5 level(1:47500000) & $\sqrt{ }$ & $\sqrt{ }$ & $\sqrt{ }$ & & & & 1.98 \\
\hline 6 level(1:23800000) & $\checkmark$ & $\checkmark$ & $\checkmark$ & & & & 0.47 \\
\hline 7 level(1:1190000) & $\checkmark$ & $\sqrt{ }$ & $\checkmark$ & $\checkmark$ & $\checkmark$ & & 1.13 \\
\hline 8 level(1:5900000) & $\sqrt{ }$ & $\sqrt{ }$ & $\sqrt{ }$ & $\sqrt{ }$ & $\sqrt{ }$ & & 0.28 \\
\hline 9 level(1:2900000) & $\sqrt{ }$ & $\sqrt{ }$ & $\sqrt{ }$ & $\sqrt{ }$ & $\sqrt{ }$ & $\sqrt{ }$ & 0.93 \\
\hline
\end{tabular}

Tab 2 Place names display under the gravitational field rule $(\bigcirc$ represents part of place names are displayed)

\begin{tabular}{|c|c|c|c|c|c|c|c|}
\hline & $\begin{array}{c}\text { Special } \\
\text { Administrative } \\
\text { Region / } \\
\text { municipality }\end{array}$ & $\begin{array}{c}\text { provincial } \\
\text { capital }\end{array}$ & $\begin{array}{c}\text { Prefecture level } \\
\text { city/ Autonomous } \\
\text { Prefecture/ } \\
\text { League/ area }\end{array}$ & $\begin{array}{c}\text { municipal } \\
\text { district }\end{array}$ & $\begin{array}{c}\text { County/ county- } \\
\text { level cities / } \\
\text { other }\end{array}$ & $\begin{array}{l}\text { Xiang/ } \\
\text { town/ } \\
\text { other }\end{array}$ & $\begin{array}{c}\text { Map lable load } \\
\mathrm{mm} 2 / \mathrm{cm} 2)\end{array}$ \\
\hline 3 level(1:19000000) & $\sqrt{ }$ & $\sqrt{ }$ & & & & & 2.59 \\
\hline 4 level(1:95000000) & $\sqrt{ }$ & $\sqrt{ }$ & O & & & & 3.93 \\
\hline 5 level(1:47500000) & $\sqrt{ }$ & $\sqrt{ }$ & $\sqrt{ }$ & & & & 1.98 \\
\hline 6 level(1:23800000) & $\checkmark$ & $\sqrt{ }$ & $\sqrt{ }$ & O & O & & 2.72 \\
\hline 7 level(1:1190000) & $\sqrt{ }$ & $\sqrt{ }$ & $\sqrt{ }$ & $\checkmark$ & $\sqrt{ }$ & & 1.13 \\
\hline 8 level(1:5900000) & $\sqrt{ }$ & $\sqrt{ }$ & $\checkmark$ & $\checkmark$ & $\sqrt{ }$ & O & 3.08 \\
\hline 9 level(1:2900000) & $\sqrt{ }$ & $\sqrt{ }$ & $\checkmark$ & $\sqrt{ }$ & $\sqrt{ }$ & $\sqrt{ }$ & 0.93 \\
\hline
\end{tabular}

\section{GRAVITY DISPLAY RULE}

\subsection{ASSUMPTIONS AND THE ESTABLISHMENT PRINCIPLE}

The gravity display rule is based on following two assumptions:
(1)Due to the dotted label can display in different levels, it is assumed that there is no conflict and overlap problems or conflicts and overlap problems have been solved.

(2)Suppose that the user is accustomed to take high-level dotted label as a reference for other place label.

The core idea of the display rule is considering high-level dotted label as the center of gravity field, which radiates around 
along with the map scale changes. When the map scale become larger, low grade dotted label also gradually become the center of gravity field, and then radiates around. As shown in Figure 1.

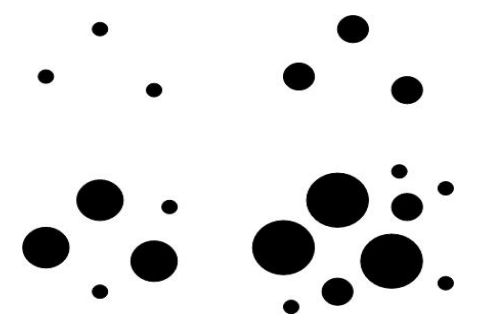

Figure 1 Gravity display rules

The two rings around the gravity center divide the map into three regions. The area close to the gravity center is called "gravity zone". In addition to show the location of label in the gravity center, "Gravity zone" also shows low-level label around the gravity center. The area between inner and outer ring is called "avoidance zone". "Avoidance zone" need to hide lowlevel label. The outer ring outside the region is named "periphery area". "Periphery area" is not affected by the gravity center, label displays according to the original rules. As shown in Figure 2.

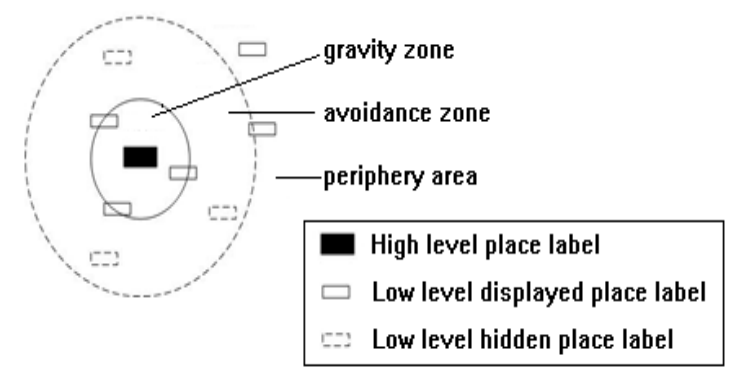

Fig 2 The composition of region and place names display rule

The rule need to solve two key problems: one is the range setting of three areas; second is the conflict between multiple gravity areas.

\subsection{THE RANGE SETTING AND ZONE CONFLICT}

The basic requirement for gravity zone is that gravity label must display completely in this region, Including Dotted label of four or eight direction. The minimum value of gravity zone radius can be determined by the following formula. As shown in Figure 3.
$\mathrm{R} \geqslant \mathrm{L}+\mathrm{h}+\mathrm{r}$
R- Gravity zone radius
L- Label width
h- The interval between symbols and labels
R-label symbols radius

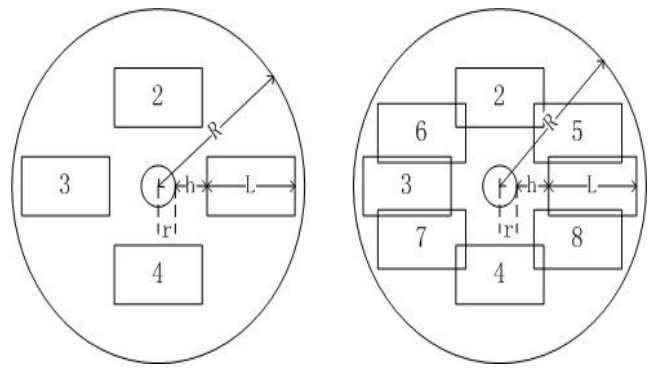

Fig 3 The minimum value of gravity zone radius

"Avoidance zone" is similar to the "Blank" in art creation and photographic composition. As shown in Figure 4.

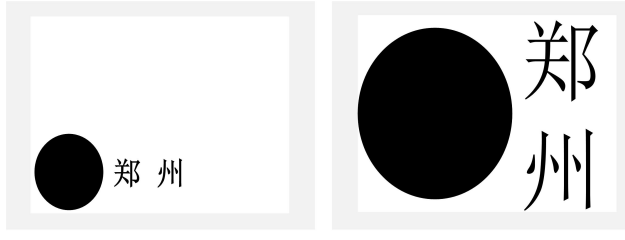

Fig 4 Avoidance zone example

Fig 4 You can focus on “郑州” easily on this image because the object does not occupy the whole page (left).You find it difficult to focus on “郑州” since you cannot catch the circle and the text at the same time because the object is too large and it occupies the page completely(right).

But the area ratio between target area and background area does not have a clear value, usually relying on art or photography master's intuition and experience. This paper calculates the area ratio between target and background of twenty-five classic white photography [10], the average ratio is about $1 / 3$. Therefore, this paper sets the outer ring radius of 2 times to inner radius, meet the area ratio that gravitational area / avoidance $1 / 3$.

Due to the presence of multiple gravity zones, a location on the map may be the avoidance zone of gravity center A, but also the gravity zone of $\mathrm{B}$. In the above situation, label display follows the priority rule "gravity zone $>$ avoidance zone>periphery zone". For example, a label named " $X$ " is in the peripheral zone of the $\mathrm{B}$, and also in the avoidance zone of $\mathrm{A}$, it should be hidden. Similarly, if " $X$ " is in the avoidance zone of $\mathrm{B}$, and also in the gravity zone of A, it should display.

\subsection{ThE SHORTAGE IN APPLICATION AND SOLUTIONS}

Based on the resident data of national 50 million level and some areas 250 thousand level (including the provinces / autonomous regions, Special Administrative Region / municipalities, provincial, prefecture-level city / Autonomous Prefecture / League / area, part of the city districts, counties / county-level city / other, part of township / town / other place 
The International Archives of the Photogrammetry, Remote Sensing and Spatial Information Sciences, Volume XL-4/W3, 2013 ISPRS/IGU/ICA Joint Workshop on Borderlands Modelling and Understanding for Global Sustainability 2013,

\section{5 - 6 December 2013, Beijing, China}

label, altogether 7060), the rule was applied in the place label display from the national level to the city level. Compared with other display rules in the ArcGIS9.3 platform, the rule can effectively solve the aforementioned problems that "high-level place label is too eye-catching, easy to distract the user" and "when user zoom in and out the map, easy to lose the interested place label".

(1)Within the same scale, high-level place label is not highlighted through significant colors, font size, but through a natural hollow ring around it, this method can highlight the highlevel place label, but also avoid influencing the reading experience of other low-level labels when the high-level place label is too bold. At the same time, because not using contrasting colors to enhance high-level place label, the number of map colors reduce, that is beneficial to the harmony of whole surface.

(2)Under different scales, while place labels changing with the map scale, the map is showing gradual expansion and contraction of graphics. At the same time, because of the hue and word size do not change dramatically, the user is not easy to lose the place name.

But the place names of the same level cannot occur simultaneously on the same scale as the existence of "Avoidance zone ", it is easy to confuse the user. So the rule should not apply to all scales in practice, but in several low cartographic label load scale, as shown in Table 2, while the other levels still follow the conventional label display rules. It's shown in Fig 5 that place labels display in the fourth level scale under the general rule and the gravity field rule.

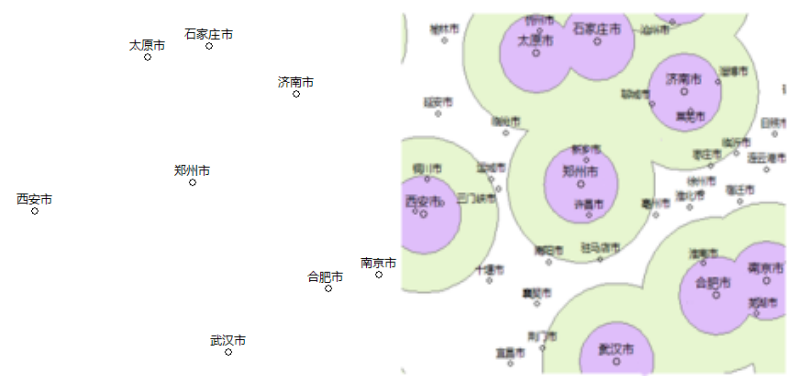

Fig5 Place names display under the general rule (left) and place name display under the gravitational field rule (right)

Compared to table 1, the fourth, sixth and eighth level in table 2, due to the application of gravity field rule, some resident labels in low level are also displayed, significantly improve the load of resident label, but the value is still far lower than the most appropriate load of resident label, so as to ensure resident label no conflict, no overlap, and clear.

\section{GRAVITY FIELD DISPLAY RULES OF USABILITY}

\section{TESTING}

In order to evaluate the validity of the rule, this paper designs two sub experiments. Each experiment included exercises and experimental stage. Participants are college students (15 boys, 9 girls), and participate in the experiment voluntarily, their average age is 21 years (19-22 years) and their naked vision or corrected vision is normal. The subjects sit at a distance of about $50 \mathrm{~cm}$ on the computer. Under the instruction, participants operate the mouse and keyboard to complete the required tasks quickly and accurately as far as possible. When the Participants can successfully complete tasks 10 times at one time, it proved that Participants has been completely familiar with the process of experiment and can enter the experimental stage. Besides the task and practice phase are different in different experimental stage, the other are the same. During the whole experiment process, the program will automatically record the action of the mouse and keyboard, the completion time and the personal data that participants fill in before the experiment, in addition, screenshots software will automatically record each participant's video

\subsection{EXPERIMENT 1}

\subsubsection{EXPERIMENT PURPOSE}

Due to the application of gravity field rule in the fourth, sixth and eighth level, the load of place label has been increased. This experiment aims to test in what extent the increase of load through the gravity field rule affects the user's recognition on place label of high-level.

\subsubsection{EXPERIMENTAL DESIGN}

In the fourth, sixth and eighth level of scale, take the provincial administrative as the center or municipalities (4th level), prefecture level city (6th level) and country (8th level) as the center, in accordance with general label display rule (Table 1) and "gravity field" rule (Table 2) we respectively draw static map. The subjects are asked to find the corresponding names on the map, such as "find Beijing", the experiment will not finished until subjects click to the place names. Take Beijing for example, the participants will test in two maps in Figure 6. 
The International Archives of the Photogrammetry, Remote Sensing and Spatial Information Sciences, Volume XL-4/W3, 2013 ISPRS/IGU/ICA Joint Workshop on Borderlands Modelling and Understanding for Global Sustainability 2013,

\section{5 - 6 December 2013, Beijing, China}

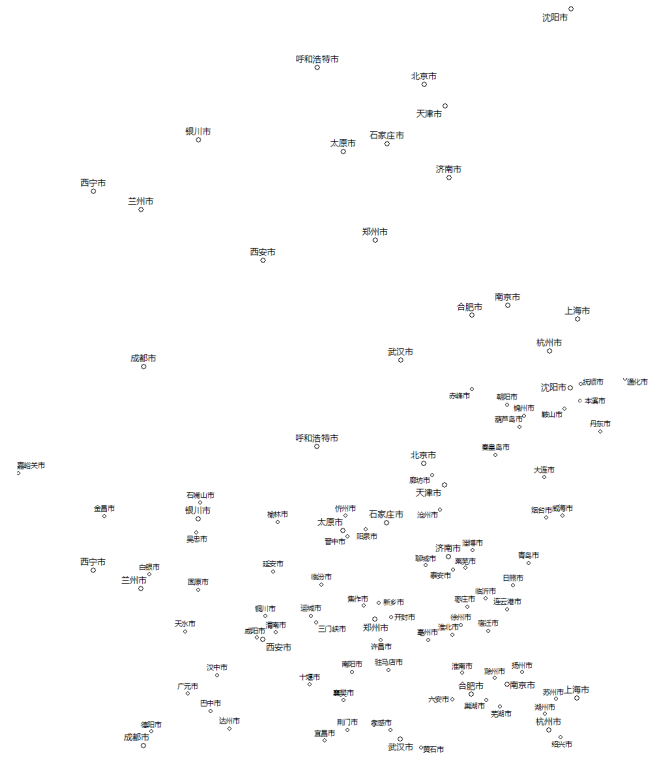

Fig6 place names display under the general rule(top) and u place name display under the gravitational field rule (bottom)

Before the experiment, we told the subjects how to operate in the experiment and the subjects were required be familiar to the process as far as possible. In order to get accurate objective test result, we make a Latin square of the order of the task.

\subsubsection{RESULT}

Statistical results as shown in Table 3, under the gravity field display rule, the average time to find names is slower than the average time under the general rule, but the gravity field display rule can make the map load significantly improved. The time under gravity field display rule mean lower 168.23 milliseconds, $15.4 \%$ slower relative to the time under the general display rule, but the map load is increased by 6.89 times.

Tab3 The average/standard deviation time (milliseconds) for two kinds of maps and map load values $(\mathrm{mm} 2 / \mathrm{cm} 2)$

\begin{tabular}{lcc}
\hline \multicolumn{1}{c}{ M style } & Mean / standard deviation & Map loading \\
\hline General display rules & $1091.78 / 377.05$ & 0.47 \\
\hline Display rules of gravity & $1260.03 / 103.96$ & 3.24 \\
field & & \\
\hline
\end{tabular}

\subsection{EXPERIMENT 2}

\subsubsection{EXPERIMENT PURPOSE}

Experiment two aims to test whether the gravity field display rule can effectively improve the users speed in finding the residents, so as to improve the readability of web map.

\subsubsection{EXPERIMENTAL DESIGN}

Unlike the static map adopted in Experiment one, the dynamic map was used in Experiment two. According to two different display rules, the corresponding map were made through ArcGIS firstly, and then the user use the zoom and roaming tool to find the place, at the same time, records mouse action, keyboard action and completion time through a program. In addition, the place labels Participants need to find are also different from Experiment one, the place labels are divided into two categories: one is not familiar to Participants, and the other is very familiar to Participants, such as home or workplace. Before the lookup, users will get some text prompt. Such as "please find Zhongmu County in map, east of the city of Zhengzhou in Henan."

\subsubsection{RESULT}

Statistical results as shown in table 4 . In the search for a familiar name, gravity field display rule is faster than the general display rule, on average about 1501 milliseconds faster, but when finding strange names, gravity field display rule is slower than the general display rule, an average of 9359.33 milliseconds slower. We found the reason is that when user searched strange names, the gravity field display rule will result that names in the same administrative level do not appear in the same scale at the same time. So when the lookup names and place names occurs in the same administrative level, due to the uncertainty in locating the strange names, instead of continue zooming out, users often constantly looking for the names around high grade place label, this will reduce the efficiency of finding names.

Tab 4 The average/standard deviation time (milliseconds) for two kinds of maps

\begin{tabular}{lcc}
\hline \multirow{2}{*}{ map style } & \multicolumn{2}{c}{ Place label style } \\
\cline { 2 - 3 } & unfamiliar & familiar \\
\hline General display rules & $18068 / 4671.28$ & $9043.67 / 947.11$ \\
\hline Display rules of gravity field & $27427.33 / 3379.45$ & $7542.67 / 860.07$ \\
\hline
\end{tabular}

\section{CONCLUSION}

Through the above experiments, we can draw the following conclusions.

(1)Compared with the general place label rule, the gravity field rule will increased label load 5 to 6 times in certain scale, in some extent which influence the user to identify the place label of the high level, but the effect is not significant.

(2)Gravity field rule will significantly improve the efficiency for searching familiar place name, but does not significantly increase the efficiency for strange names; indeed, it will reduce the efficiency. In the actual practice, when finding familiar names, user usually uses the zoom and roams tools, and when finding the strange names, user is more inclined to use the search tool. Therefore, it makes up for the lack of gravity field rule in search of the strange names in some extent. 
The International Archives of the Photogrammetry, Remote Sensing and Spatial Information Sciences, Volume XL-4/W3, 2013 ISPRS/IGU/ICA Joint Workshop on Borderlands Modelling and Understanding for Global Sustainability 2013,

$$
5 \text { - } 6 \text { December 2013, Beijing, China }
$$

In summary, the gravity field rule is applicable to the place label display of web map, and it can effectively improve the legibility of web map dotted names.

REFERENCE

[1] Arthur H.Robinson. The Look of Maps An Examination of Cartographic Design[M].NewYork: ESRI Press,2010.

[2] J.G.Withycombe. Lettering on

Maps[J], Geog.Journal.1929,73:429-446

[3]Yoeli P. The logic of automated map lettering. The

Cartographical Journal.1972,9(2):99-108

[4]Imhof E. Positioning names on maps. The American Cartographer,1975,2(2):128-144

[5] Ling Shanjin, Huang Shuling, Liang Dongdong. Design of map annotation study[J]. Journal of Anhwei Normal

University, 2007, 30(5): 603-606.
[6]Justin O’Beirne, Goolgle Maps\&Label

Readability[EB/OL].[2010-12-2][2011-2-

10].http://www.41latitude.com/post/2072504768/google-mapslabel-readability.

[7] Wang Jian, Zhao Zhifang. Size Threshold of Chinese characters and Appropriate Character-space in Electronic Map[J].applied psychology, 2008， 14(1):60-65

[8] Wang Liuyi. Research and Practice on Experiments of Electronic Maps [D]. Master's degree thesis of The PLA Information Engineering University

[9] Fan Hong. Research of map automatic labeling[M].BeiJing: The publishing house of Surveying and mapping, 2004.

[10] fandy, Beautiful Photography Used Negative Space echnique[EB/OL][2010-7-13][2012-12-7].

http://www.artfans.info/beautiful-photography-used-negativespace-technique/ 